\title{
Teaching nursing students to provide effective heart failure patient education using a peer teaching strategy
}

\author{
Margaret A. Avallone, E. Renee Cantwell \\ Rutgers University School of Nursing-Camden, Camden, New Jersey, United States
}

Received: July 29, 2016

DOI: $10.5430 /$ jnep.v7n2p84
Accepted: September 18, 2016 Online Published: September 27, 2016

URL: http://dx.doi.org/10.5430/jnep.v7n2p84

\begin{abstract}
Background/objective: Prelicensure nursing students possess minimal knowledge, skills, and confidence to provide effective, patient-centered transitional heart failure (HF) education to patients. This article evaluates a unique educational intervention designed to prepare nursing students to be more effective HF patient educators upon graduation.

Methods: A pretest, posttest design and survey was used to evaluate a three-hour educational program. This program was offered to three different groups of students between Fall 2013 and Spring 2016. Eighteen fourth-semester students trained as peer teachers helped present program content to 66 second-semester Accelerated Bachelor of Science (ABS) nursing students. Resources from the Institute for Healthcare Improvement (IHI) and the Robert Wood Johnson Foundation Transforming Care at the Bedside (TCAB) materials were used as the curricular guide. The program consisted of a HF didactic session, case study, role-play, and simulation activities.

Results: Second-semester students demonstrated improvement in identifying essential elements of HF patient education, from $45.8 \%$ to $86 \%$, and the ability to perform Teach-back increased from $43 \%$ to $86 \%(p<.001)$. Confidence in patient education skills and Teach-Back technique increased from $17 \%$ to $94 \%(p<.001)$.

Conclusions: Using fourth-semester peer teachers to facilitate education provides an effective and satisfying way for the second semester students to practice new techniques through role-play. The HF peer teaching program is highly adaptable to prepare prelicensure nursing students to educate patients and families on a wide variety of chronic illnesses across the healthcare continuum.
\end{abstract}

Key Words: Heart failure, Patient education, Nursing student, Peer teaching

\section{INTRODUCTION}

Heart failure affects an estimated 26 million individuals across the world ${ }^{[1]}$ and is the leading cause of hospitalization in the United States and Europe. Effective patient-centered education is an essential part of an overall strategy to assist patients as they transition from hospital to home or other clinical setting. Graduate nurses must possess knowledge of heart failure (HF) self-care principles as well as patient education skills that can help prepare patients for transition from the hospital setting. Though prelicensure nursing students may learn HF concepts and transitional care content as part of the curriculum, they may not possess the confidence, knowledge, or skills to provide effective, patient-centered HF education to patients. Heart failure self care was used as a template to teach nursing students transitional care concepts and skills. This article describes an innovative educational program using a peer teaching strategy designed to prepare prelicensure nursing students to become more effective par-

*Correspondence: Margaret A. Avallone; Email: margaret.avallone@ rutgers.edu; Address: Rutgers University School of Nursing-Camden 215 N. 3rd St. Camden, United States. 
ticipants of the HF transitional care team.

\subsection{Aim and research questions}

The aim of this educational project was to assess the effect of a HF Peer Teaching program in developing prelicensure nursing students' knowledge of essential HF concepts, patient teaching confidence, and utilization of Teach-back. The following program evaluation questions were asked:

- Would the HF Peer Teaching program positively affect knowledge of Essential HF transitional patient education compared to baseline knowledge?

- Would the HF Peer Teaching program positively affect student confidence in their ability to perform HF patient education compared to baseline?

- Would students the HF Peer Teaching program report increased knowledge and confidence in students' ability to utilize Teach-Back health literacy techniques compared to baseline measures?

\subsection{Background}

With approximately 875,000 new cases diagnosed each year, $\mathrm{HF}$ is the leading diagnosis of hospitalized patients over the age of 65 years, and is the most frequent cause of readmissions to the hospital. ${ }^{[2]}$ In the United States (U.S.), approximately $20 \%$ of elderly HF patients are readmitted within 30 days. ${ }^{[3]}$ Many of these readmissions may be preventable, resulting in part from nonadherance to treatment and delays in seeking medical attention. ${ }^{[4]}$

\subsection{Heart failure education and improved patient out- comes}

Hospital nursing staff are frequently a front line contact and vital link providing HF education for patients and families. One strategy for decreasing readmissions is for nursing staff to provide quality discharge teaching ${ }^{[5]}$ (Lacker, 2011). Several studies suggest that increasing the staff nurses' knowledge of heart failure concepts will result in improved patient outcomes and decreased HF readmissions. Koelling et al. demonstrated improved clinical outcomes when providing $\mathrm{HF}$ patients with an education intervention prior to discharge ${ }^{[6]}$ and more recently, Stern et al. noted a decrease in HF readmission rates after providing a heart failure education program to staff nurses. ${ }^{[7]}$ Hart surveyed staff nurses to determine knowledge of HF education principles and found that nurses were not as well versed in HF self-management education as is needed to provide quality patient education. ${ }^{[8]}$ A multicomponent approach is more effective in reducing readmissions for heart failure when the interventions include "goal setting, care planning, educational and behavioral strategies and clinical management" ${ }^{[9]}$

Published by Sciedu Press
Quality patient education is one component of the larger group of factors related to the discharge of patients from one level of care to another, also known as transitional care. Transitional care is a set of time-limited actions that help bridge gaps in coordination and continuity of care as patients transfer between different levels of care. ${ }^{[9]}$ The Robert Wood Johnson Foundation and the Institute for Healthcare Improvement (IHI) summarized best practices that enhance the transition of HF patients being discharged from hospital to home in the document: Transforming Care at the Bedside How to Guide: Creating an Ideal Transition Home for Patients with HF. ${ }^{[10]}$ Within the IHI document are recommendations from the Heart Failure Society of America, identifying essential topics for heart failure education. ${ }^{[14]}$

\subsection{Essential elements of $\mathbf{H F}$ education}

Though knowledge alone is not sufficient to produce a change in self-care behavior, there is evidence that patients who receive quality HF education have reduced readmissions at 30 days and demonstrate longer periods until readmission, ${ }^{[11-13]}$ with the exception of patients with limited understanding or non-English speaking who had higher rates of readmissions. ${ }^{[11]}$ The Heart Failure Society of America identified "essential elements", or topics that should be taught to every inpatient patient diagnosed with $\mathrm{HF}^{\left[{ }^{[14]}\right.}$ These essential seven topics include: basic disease information, signs and symptoms of escalating disease, medication information, smoking cessation, risk factor reduction, diet, exercise and stress management and follow up care.

\subsection{Teach-back}

Providing patients information about the essential elements is important, but equally important is the way in which the information is shared. The IHI, and the Agency for Healthcare Research and Quality (AHRQ) have identified Teach-Back methodology as a best practice to promote patient-centered education. ${ }^{[15,16]}$ Teach-Back is an evidence-based health literacy strategy used to assess learners' understanding of information taught. ${ }^{[17]}$ Using Teach-Back, the health care provider explains information in patient-appropriate terms, and then asks in a non-shaming way, for the patient to recall and restate, in the patient's own words, what they have been told. The goal of Teach-Back is to provide effective patient education at the health literacy level of the patient and the caregiver. Peter et al. describe a HF educational program using Teach-Back that resulted in a reduction of 30-day and 90-day readmission rates for HF. ${ }^{[18]}$

\subsection{Peer teaching}

A Peer teaching strategy was used in the HF Peer Teaching Program. Peer teaching partnerships have been used success- 
fully in a number of settings, including nursing education, to enhance learning, reduce anxiety, develop competence, and promote professional development. ${ }^{[19-22]}$ Peer teaching is consistent with Knowles Adult Learning Theory, which supports the use of mentors, peers, and others, to meet the varied needs of the adult learner. ${ }^{[23]}$

\section{Methods}

\subsection{Project design}

A pre-test, post-test design was used. Second-semester nursing student knowledge and confidence of HF educational topics at the beginning of the three-hour HF Peer Teaching Program were compared to the same measures immediately following the program.

\subsection{Ethical considerations}

This educational project requested and received exempt status from the Institutional Review Board of the University. Participation in the study was voluntary. Participation, lack of participation, or data obtained during the evaluation had no bearing on students' course grade or progression through the nursing program.

\subsection{Measurement Instruments}

Instructor-designed pretest and post-test instruments were used to measure the difference in knowledge and confidence resulting from participation in the HF Peer Teaching Program. Topics measured included: knowledge of essential elements of patient discharge information and signs and symptoms of escalating HF symptoms. ${ }^{[14]}$ To evaluate Teach-back knowledge, participants were asked to provide an example reflecting Teach-Back wording that might be used when teaching a patient. Participants' confidence in performing HF assessment, patient education, and Teach-Back was also measured pretest and post-test with an instructor-designed Likert survey with responses ranging from one to five. The Peer Teachers were asked to evaluate the teaching strategy using an open-ended survey questionnaire.

\subsection{Participants}

The program was implemented for three student cohorts enrolled in the school of nursing between Fall 2013 through Spring 2016. One hundred and ten (110) second semester Accelerated Bachelor of Science (ABS) students enrolled in the Adult Health and Illness course at Rutgers School of Nursing-Camden were invited to participate in the HF Peer Teaching Program. Of this total number, 66 students participated. All fourth semester ABS students enrolled in the Capstone course were invited to participate as peer teachers. A total of eighteen students served as the peer teachers for this project.

\subsection{Intervention}

The HF Peer Teaching Program consisted of two parts; a twohour Peer Teacher training for fourth semester students, and a three-hour peer educational workshop for second semester nursing students.

\subsubsection{Peer teacher training}

As previously discussed, fourth semester nursing students were utilized for the peer teaching strategy to help present program content. In preparation for the three-hour HF Peer Teaching Program, fourth semester peer teachers attended a two-hour training session with one of the faculty members participating in the study to prepare for the educational program. The topics covered included HF signs and symptoms, essential elements of transitional care education for HF patients $^{[14]}$ and Teach-Back. ${ }^{[16]}$ This training was performed to assure that the peer teachers would provide accurate information to the second-semester students. The peer teachers demonstrated proficiency via achievement of a satisfactory score on the HF Education Pre-Test prior to the educational intervention. Additionally, peer teachers rehearsed role-play demonstrations of good and bad HF patient education and received constructive feedback from study faculty. Additionally, these faculty planned the agenda for the HF peer teaching Program with the Peer Teachers. The agenda was planned with all educational tasks divided up among the peer teachers.

\subsubsection{HF educational workshop}

The three-hour HF Peer Teaching Workshop utilized didactic, case study, and role-play activities within an overall peer teaching strategy to present program content. The three-hour HF Peer Teaching program for the second-semester students provided a review of HF signs and symptoms, presentation of essential elements of patient education for the HF patient transitioning to home, ${ }^{[14]}$ and explanation and demonstration of the Teach-Back health literacy. ${ }^{[16,17]}$ Along with the peer teaching strategy, teaching methods included case study examples of patients discharged with HF diagnosis and role-play of students teaching patients with HF. The peer teachers demonstrated patient education using Teachback technique, and then student learners had the opportunity for small group practice and return demonstration with peer teachers. The peer teachers facilitated the role play within the small groups of three or four second semester students for each peer teacher. Faculty were present at all times to facilitate and support the peer teachers and second semester student learners.

\section{RESULTS}

Sixty-six second-semester participants were educated in transitional HF patient education concepts by eighteen peer teach- 
ers over the course of three semesters from Fall 2013 to Spring 2016. Pre-training scores were obtained on the PreTest Instrument. Post-training scores were obtained immediately following the training program. Examination of the change scores was conducted by paired $t$-tests and Chi-sqare tests. Data were analyzed using the IBM SPSS statistical package version 22 . There was no missing data.

\subsection{Improvement in knowledge}

As shown in Table 1, second-semester students demonstrated significant improvement in identifying essential elements of HF patient education and escalating signs of HF, as defined by the IHI and TCAB: Creating an Ideal Transition Home for Patients with Heart Failure. ${ }^{[10]}$ Additionally, the program sig- nificantly improved the second-semester students' ability to demonstrate Teach-Back techniques from $43 \%$ pre-training to $86 \%$ post-training $(p<.001)$.

\subsection{Learner confidence}

The participants rated their confidence in response to three statements both before and after training:

(1) I feel confident that I can correctly perform HF assessment techniques.

(2) I feel confident that I can correctly perform HF patient education.

(3) I feel confident that I can use Teach-Back techniques in the clinical area.

Table 1. HF knowledge measures

\begin{tabular}{|c|c|c|c|c|c|}
\hline Measure & Max Score & Pre $(M)$ & Post $(M)$ & $t$-score & $p$-level \\
\hline Essential Elements & 7 & $3.21(1.45)$ & 5.42 (1.39) & 11.32 & $<.001$ \\
\hline Escalating Signs HF & 5 & 2.98 (1.38) & $4.60(0.77)$ & 7.57 & $<.001$ \\
\hline
\end{tabular}

Participants rated their confidence levels on a 5-point Likert scale ranging from Strongly Disagree to Strongly Agree. For analysis purposes with 66 participants, the 5-point scale was collapsed into two ratings: Disagree/Neutral and Agree. As shown in Table 2, the confidence ratings of the participants were significantly improved after training. Yate's correction was applied to the Chi-Square analyses for $2 \times 2$ tables.

\subsection{Peer teacher evaluation}

The peer teachers evaluated the HF Peer Teaching Program at the conclusion of the program in an open-ended survey. All 18 peer teachers described the program as an effective method for teaching HF patient education. Their comments were as follows: "This is a great way to reinforce information to students", "It helps to hear the same information in different ways: such as demonstration and role play", "It is a really good way to show different example of how to learn"; "This was a good teaching method, not only for second semester students, but for the fourth semester students as well"; "Would recommend doing this type of thing more often", "We can relate to what the students in Adult Health are going through, so this was a great program", "I felt I considered the learning needs of the second-semester students", "I felt that the second-semester students respected my position as a peer teacher", "I felt this program gave me confidence as a leader".

Table 2. Confidence measures

\begin{tabular}{lllll}
\hline Topic & Pre-Training Agreement & Post-Training Agreement & Chi-Square (Yates) & Probability \\
\hline HF Assessment & $17 \%$ & $94 \%$ & 61.16 & $<.0001$ \\
HF Patient Education & $9 \%$ & $100 \%$ & 84.11 & $<.0001$ \\
Teach-Back technique & $17 \%$ & $100 \%$ & 71.85 & $<.0001$ \\
\hline
\end{tabular}

\section{Discussion}

The findings from this educational project suggest that the HF Peer Teaching Program may be an effective mechanism for teaching nursing students' essential concepts of HF patient education. It is also suggested that the program effectively conveyed beginning skills in Teach-Back technique. There was significant improvement in Adult health students' knowledge of the Essential Elements of HF patient education, as well as significant improvement in Knowledge of Escalating Signs of HF. Additionally, second-semester students'

Published by Sciedu Press confidence in their ability to provide HF education to patients increased significantly. The fourth semester students described the program as an overwhelmingly positive experience and one that supported development of their leadership skills.

The HF Peer Teaching Program was effective in terms of improvement in cognitive knowledge of HF, patient education topics, Teach-Back, and student confidence in ability to perform patient education. Its impact could be substantial in that 
students who are able to provide HF education effectively using Teach Back technique may be able to implement this method in discharge teaching for all patients whatever their discharge diagnosis. Effective discharge instruction may lead to improved patient safety and quality care.

The IHI and TCAB How-To Guide: Creating an Ideal Transition Home for patients with $\mathrm{HF}^{[10]}$ provides a template to learn transitional care education that nursing students can use and apply to other chronic disease states. The HF Peer Teaching Program may provide an exemplar for nursing students to gain patient education knowledge, skills, and confidence so that they will be better equipped to teach patients and families who are managing other chronic disease states. Instructing students in the use of Teach-Back technique provides an evidence-based, patient-centered method for teaching patients. ${ }^{[24]}$

The use of a peer teaching strategy greatly enhanced the entire teaching and learning process for both the second semester and fourth semester students. The student evaluations revealed unexpected benefits that went beyond the gains in HF knowledge and confidence. Second-semester students stated, "I really loved learning from the peer teachers. They made learning non-stressful and enjoyable. Seeing how knowledgeable they were gave me hope that I can make it in this program and be successful. Another student said, "The peer teachers were so supportive and helpful". "In our groups, the peer teachers were really encouraging and gave us tips to help us be successful in the program". It takes more work and planning to prepare peer teachers to teach. However, students are uniquely qualified in many ways to deliver content to other students in creative and relevant ways. Each cohort of peer teachers surprised the professors with their ingenuity, enthusiasm, and creativity.

\section{LIMITATIONS AND IMPLICATIONS FOR FU- TURE STUDY}

The program was limited in its scope. While student knowledge and confidence was measurably increased during an educational program, it is unclear if this change in knowledge and confidence will be sustained and will translate to improved HF patient education at the bedside. Follow up is planned to augment the HF Peer Teaching Program with opportunities for students to provide education and return demonstration with heart failure patients in acute care and clinic settings, mentored by heart failure RN educators.

A second limitation of the project evaluation was that the tools used were designed by the investigator to meet local curricular improvement needs. While the tools met a local curricular need, the results obtained may not be generalizable to other Schools of Nursing.

\section{Conclusion}

HF is a growing healthcare issue because of its high prevalence, and its growing clinical and economic impact in the U.S. and world. It is estimated that by 2030 , one in 33 persons over the age of 65 will be diagnosed with HF. ${ }^{[25]}$ The bedside nurse must possess the knowledge and skills to assess and provide effective patient and family education as part of an overall transitional care and disease management strategy. Schools of Nursing must prepare graduating prelicensure nursing students with the knowledge, skills, and attitudes necessary to provide effective transitional care for patients. The HF Peer Teaching program demonstrated effectiveness by improving students' knowledge and confidence of essential HF patient education topics. Additionally, students demonstrated knowledge and confidence in their ability to perform the students' knowledge of essential topics to be included in patient education, and in the Teach-Back technique to assess patient understanding of information presented.

\section{ACKNOWLEDGEMENTS}

The authors wish to thank Dennis Carmody, PhD, for his assistance with statistical analysis.

\section{CONFlicts of InTERest Disclosure}

The authors declare that there is no conflict of interest.

\section{REFERENCES}

[1] Ambrosy AP, Fonarow GC, Butler J, et al. The global health and economic burden of hospitalizations for heart failure: lessons learned from hospitalized heart failure registries. Journal of the American College of Cardiology. 2014; 63(12): 1123-33. PMid:24491689 http://dx.doi.org/10.1016/j.jacc.2013.11.053

[2] Hernandez AF, Greiner MA, Fonarow GC, et al. Relationship between early physician follow-up and 30-day readmission among medicare beneficiaries hospitalized for heart failure. Journal of the Ameri- can Medical Association. 2010; 303(17): 1716-22. PMid:20442387 http://dx.doi.org/10.1001/jama.2010.533

[3] Fida N, Pina IL. Trends in heart failure hospitalizations. Current Heart Failure Reports. 2012; 9(4): 346-53. PMid:23070579 http: //dx.doi.org/10.1007/s11897-012-0117-5

[4] Prasun MA. Heart failure patient education. Heart \& lung : The Journal of Critical Care. 2014; 43(6): 485. PMid:25242118 http: //dx.doi.org/10.1016/j.hrtlng.2014.08.002

[5] Lacker C. Decreasing 30-day readmission rates. The American 
Journal of Nursing. 2011; 111(11): 65-9. PMid:22030933 http: //dx.doi.org/10.1097/01.NAJ.0000407308.53587.02

[6] Koelling TM, Johnson ML, Cody RJ, et al. Discharge education improves clinical outcomes in patients with chronic heart failure. Circulation. 2005; 111(2): 179-85. PMid:15642765 http://dx.d oi.org/10.1161/01.CIR.0000151811.53450.B8

[7] Sterne PP, Grossman S, Migliardi JS, et al. Nurses' Knowledge of Heart Failure: Implications for Decreasing 30-Day Re-Admission Rates. Medsurg Nursing: Official Journal of the Academy of MedicalSurgical Nurses. 2014; 23(5): 321-9.

[8] Hart PL, Spiva L, Kimble LP. Nurses' knowledge of heart failure education principles survey: a psychometric. J Clin Nurs. 2011; 20(21-22): 3020-8. PMid:21615575 http://dx.doi.org/10.11 $11 / j \cdot 1365-2702.2011 .03717 . x$

[9] Naylor MD, Aiken LH, Kurtzman ET, et al. The care span: The importance of transitional care in achieving health reform. Health Affairs. 2011; 30(4): 746-54. PMid:21471497 http://dx.doi.o $\mathrm{rg} / 10.1377 / \mathrm{hl}$ thaff. 2011.0041

[10] Nielsen GA, et al. Transforming care at the bedside how-to guide: Creating an ideal transition home for patients with heart failure. Cambridge, MA: Institute for Healthcare Improvement. 2008. Transforming care at the bedside how-to guide: Creating an ideal transition home for patients with heart failure. Cambridge, MA: Institute for Healthcare Improvement; 2008.

[11] Regalbuto R, Maurer MS, Chapel D, et al. Joint Commission requirements for discharge instructions in patients with heart failure: is understanding important for preventing readmissions? Journal of Cardiac Failure. 2014; 20(9): 641-9. PMid:24996200 http: //dx.doi.org/10.1016/j.cardfail.2014.06.358

[12] Stamp KD, Machado MA, Allen NA. Transitional care programs improve outcomes for heart failure patients: an integrative review. The Journal of Cardiovascular Nursing. 2014; 29(2): 14054. PMid:23348223 http://dx.doi.org/10.1097/JCN. 0 b013 e31827db560

[13] VanSuch M, Naessens JM, Stroebel RJ, et al. Effect of discharge instructions on readmission of hospitalised patients with heart failure: do all of the Joint Commission on Accreditation of Healthcare Organizations heart failure core measures reflect better care? Quality \& Safety in Health Care. 2006; 15(6): 414-7. PMid:17142589 http://dx.doi.org/10.1136/qshc. 2005.017640

[14] Lindenfeld J, Albert NM, Boehmer JP, et al. HFSA 2010 Comprehensive Heart Failure Practice Guideline. Journal of Cardiac Failure.
2010; 16(6): e1-194. PMid:20610207 http://dx.doi.org/10. 1016/j. cardfail. 2010.04.004

[15] Institute for Healthcare Improvement (IHI). Available from: http://www.ihi.org/resources/Pages/Tools/AlwaysUseT eachBack! . aspx

[16] Agency for Healthcare Research and Quality (AHRQ). Health Literacy Universal Precautions Toolkit. Available from: http: //www.ahrq.gov/sites/default/files/wysiwyg/profess ionals/quality-patient-safety/quality-resources/t ools/literacy-toolkit/healthliteracytoolkit.pdf

[17] Rudd RE. Improving Americans' health literacy. The New England Journal of Medicine. 2010; 363(24): 2283-5. PMid:21142532 http://dx.doi.org/10.1056/NEJMp1008755

[18] Peter D, Robinson P, Jordan M, et al. Reducing readmissions using teach-back: enhancing patient and family education. J Nurs Adm. 2015; 45(1): 35-42. PMid:25479173 http://dx.doi.org/10.10 97/NNA. 0000000000000155

[19] Cooper JR, Martin T, Fisher W, et al. Peer-to-peer teaching: improving communication techniques for students in an accelerated nursing program. Nursing Education Perspectives. 2013; 34(5): 34950. http://dx. doi.org/10.5480/1536-5026-34.5.349

[20] Teach-back program reduces readmissions. Healthcare Benchmarks and Quality Improvement. 2011; 18(11): 123-5. PMid:22039616

[21] Li HC, Wang LS, Lin YH, et al. The effect of a peer-mentoring strategy on student nurse stress reduction in clinical practice. Int Nurs Rev. 2011; 58(2): 203-10. PMid:21554294 http://dx.doi.org/1 $0.1111 / j .1466-7657.2010 .00839 . x$

[22] Secomb J. A systematic review of peer teaching and learning in clinical education. J Clin Nurs. 2008; 17(6): 703-16. PMid:18047577 http://dx.doi.org/10.1111/j.1365-2702.2007.01954.x

[23] Knowles M. The Adult Learner: A Neglected Species. third ed. Houston: Gulf Publishing Co.; 1984.

[24] Fidyk L, Ventura K, Green K. Teaching nurses how to teach: strategies to enhance the quality of patient education. Journal for Nurses in Professional Development. 2014; 30(5): 248-53. PMid:25237917 http://dx.doi.org/10.1097/NND.0000000000000074

[25] Heidenreich PA, Albert NM, Allen LA, et al. Forecasting the impact of heart failure in the United States: a policy statement from the American Heart Association. Circulation Heart failure. 2013; 6(3): 606-19. PMid:23616602 http://dx.doi.org/10.1161/H HF. Ob013e318291329a 